\title{
A HOMOFOBIA CONTRA O PROFESSOR “PRIMÁRIO” DO SEXO MASCULINO
}

\author{
LA HOMOFOBIA CONTRA EL PROFESOR DE EDUCACIÓN PRIMARIA DE SEXO MASCULINO
}

\section{HOMOPHOBIA AGAINST THE MALE ELEMENTARY TEACHER}

\section{RESUMO}

Este artigo apresenta um estudo comparativo sobre o professor do sexo masculino que trabalha no ensino público do "ensino primário" do Rio de Janeiro - Brasil e em Aveiro - Portugal. O que se pretendeu averiguar, fundamentalmente, foram as consequências da escolha profissional destes professores que se enveredam por uma área tipicamente associada com o feminino, uma associação tão forte que estes professores parecem um "corpo estranho" no cotidiano das escolas públicas "primárias". Utilizamos a metodologia de investigação quantitativos e qualitativos de acordo com um modelo multimodal e misto de investigação que converge tais enfoques aproveitando as suas vantagens, foram aplicados questionários e realizadas entrevistas narrativas. A pesquisa tem base em uma amostra de 209 professores do ensino público que responderam anteriormente a um questionário (objetivo e subjetivo), 6o do Distrito de Aveiro (Portugal) e 149 do Estado do Rio de Janeiro (Brasil), bem como em entrevistas com seis professores escolhidos ao acaso, 3 professores no Brasil e 3 em Portugal com diferentes faixas etárias. Percebemos que estes professores são homens que estão na escola repensando os papéis masculinos e femininos nas profissões e, por estar introduzindo mudanças nos papéis de gênero, acabam por sofrer muitas discriminações, uma delas é a homofobia contra este professor.

Palavras-chave: Discriminação de gênero. Professores. Homem. Homofobia.

\section{RESUMEN}

En este artículo se presenta un estudio comparativo sobre el profesor de sexo masculino que trabaja en las escuelas públicas "primarias" en Río de Janeiro (Brasil) y Aveiro (Portugal). Lo que intentamos averiguar, fundamentalmente, las consecuencias de la elección de carrera de los profesores que están adoptando un área típicamente asociada con el sexo femenino, una asociación tan fuerte que estos profesores parecen un "cuerpo extraño" en la vida cotidiana de las escuelas públicas "primarias". Utilizamos la metodología de investigación cuantitativa y cualitativa de acuerdo con un modelo de investigación multimodal y mixto que converge tales enfoques aprovechando sus ventajas, se aplicaron cuestionarios y se realizaron entrevistas narrativas. La investigación se basa en una muestra de 209 maestros de escuelas públicas que respondieron previamente a un cuestionario (objetivo y

Amanda Oliveira Rabelo

Professora Associada da UFF - Brasil. E-mail: amandaorabelo@hotmail.com 
subjetivo), 6o del Distrito de Aveiro (Portugal) y 149 del Estado de Río de Janeiro (Brasil), así como en entrevistas con seis maestros elegidos al azar, 3 maestros en Brasil y 3 en Portugal con diferentes grupos de edad. Somos conscientes de que estos profesores son hombres que se están replanteando en la escuela los papeles masculinos y femeninos en las profesiones y que se introduzcan cambios en las funciones de género, en última instancia, están sujetos a muchas discriminaciones, una de ellas es la homofobia contra este profesor.

Palabras clave: Discriminación de género. Profesores. Hombre. Homofobia.

\begin{abstract}
This paper presents a comparative study about the male teacher who works in the elementary public education in Rio de Janeiro - Brazil and in Aveiro - Portugal. We intended, fundamentally, to investigate the consequences of teachers' professional choice who are engaged in area typically associated to women, this association is so strong that these teachers looks like a "foreign body" in quotidian of "elementary" public schools. We use the quantitative and qualitative research methodology according to a multimodal and mixed research model that converges such approaches taking advantage of their advantages, questionnaires were applied and narrative interviews were conducted. The research is based on a sample of 209 public school teachers who previously answered a questionnaire (objective and subjective), 6o from the Aveiro District (Portugal) and 149 from the Rio de Janeiro State (Brazil), as well as in interviews with six teachers chosen at random, 3 teachers in Brazil and 3 in Portugal with different age groups. They are men who are at school rethinking the men and women roles in the professions. Because of this they suffer lots of discriminations, one of these discrimination is the homophobia against male teachers.
\end{abstract}

Keywords: Gender discrimination. Teachers. Male. Homophobia.

\title{
Introdução
}

As representações estão carregadas de discursos e preconceitos que podem diferenciar as práticas e escolhas (nos apoiamos nas considerações de representações de MOSCOVICI, 1988), inclusive as relacionadas com a profissão, pois existem profissões que são socialmente definidas como femininas ou masculinas, assim como as representações que as cercam. Deste modo, a docência tem sido historicamente envolvida de várias representações de gênero, representações que a associam com o feminino e que divulgam que os professores homens estariam fora de lugar.

Assim, analisamos que as representações ajudam a formar um discurso sobre o magistério enquanto profissão feminina. Como aponta Sayão (2005, p. 216) a convivência dos homens em espaços de intensa feminilidade propicia uma revaloração das masculinidades e das feminilidades, bem como dos processos identitários dos/ as diferentes profissionais no magistério, até porque o ideal de ser reconhecido como 
homem pressupõe certas provas e contra provas. Carvalho (1998, p. 6) também refere que os professores do sexo masculino podem ajudar na apreensão da feminização da docência enquanto processo de construção social de significados de gênero feminino para a docência primária, pois lidam constantemente com expectativas e tarefas culturalmente associados à feminilidade e, por isso, digladiam-se com as questões relativas ao gênero, imersos numa carreira socialmente desvalorizada, com salário e prestígio baixo (no Brasil) e que pressupõe habilidades e comportamentos associados à feminilidade.

Uma das questões de gênero que tange aos professores primários ${ }^{1}$ do sexo masculino são as experiências de discriminações que os professores vivenciaram ou presenciaram. Para conhecê-las realizamos entrevistas narrativas semi-estruturadas com seis professores escolhidos ao acaso, 3 professores no Brasil e 3 em Portugal com diferentes faixas etárias, dentre uma amostra de 209 professores do ensino público que responderam anteriormente a um questionário (objetivo e subjetivo), 6o do Distrito de Aveiro (Portugal) e 149 do Estado do Rio de Janeiro (Brasil)², efetuando uma análise comparada (nos apoiamos nos debates, pressupostos e desafios dessa escolha metodológica, com base em MADEIRA, 2006).

Tais dados permitiram a análise da informação obtida e forneceram dados mais amplos (pela categorização, apreciação e quantificação das estatísticas e dos discursos escritos provenientes dos questionários), assim como possibilitaram situar as informações em vivências (nas narrativas de entrevistados) ${ }^{3}$, analisando os significados presentes e a sua relação com a sociedade, as suas instituições e os seus enunciados. A combinação destes processos de recolha de dados/discursos possibilitou-nos fazer o confronto entre o geral e o local.

Nosso trabalho foi orientado pela abordagem de investigação narrativa, centrada no método qualitativo, para obter uma maior profundidade dos dados (tanto nas entrevistas como nas questões abertas do inquérito por questionário), assim como no método quantitativo, com o fim de obter também dados mais gerais sobre a temática. A informação foi recolhida através de inquéritos por questionário e entrevistas com professores "primários" do sexo masculino.

Ou seja, a metodologia que utilizamos para abarcar os nossos objetivos foi elaborada a nossa metodologia a partir de um conjunto dos processos. Desta forma, não separamos os enfoques de investigação quantitativos e qualitativos, ao contrário,

1 Utilizaremos neste trabalho o termo "ensino primário" de acordo com a Classificação Internacional Tipo da Educação da UNESCO (CITE 1, 1997, citada por Eurydice, 2001) e como tentativa de usar um termo compreensível no Brasil e em Portugal (pois este já foi utilizado em ambos os países) para designar o atual "1. ciclo do Ensino Básico (1. CEB)" de Portugal e os "anos iniciais do Ensino Fundamental” do Brasil, ambos têm um só professor que leciona todas as disciplinas (monodocência).

2 Foram distribuídos questionários a todos os professores do sexo masculino que obtivemos informação sobre a existência (muitos municípios no Rio de Janeiro (Brasil) não tinham o dado dos professores separado por gênero, o que dificultou o envio a todos os professores): 113 questionários dos agrupamentos do Distrito de Aveiro (AV-PT) e 328 das prefeituras do Estado do Rio de Janeiro (RJ-BR). Assim obtivemos uma taxa de retorno, respectivamente, de $53 \%$ e $45 \%$.

3 Assim como as informações também permitiriam que as vivências pudessem ser analisadas no que têm de singular ou comum. 
de acordo com a proposta de Sampieri et al (2006), preferimos um modelo multimodal e misto de investigação que converge tais enfoques aproveitando as suas vantagens.

Aproveitamos para explicar que este recorte espacial foi tomado e escolhido como ponto central de discussões e comparações com o intuito de captar diferenças e semelhanças entre estes dois locais, nunca esquecendo da influência da colonização portuguesa sobre a cultura e a escola brasileira, mas também destacando as características locais como forma de perceber que caminhos diferentes podem ser traçados e que estes dependem dos vários condicionantes a que se são submetidos.

As entrevistas e os questionários distribuídos a estes professores do sexo masculino no ensino público de primário do Brasil (utilizaremos a sigla RJ-BR) e Portugal (utilizaremos a sigla AV-PT) oferecem-nos pistas para que as discriminações de gênero possam ser superadas, para que tanto mulheres quanto homens não sejam alvo de discriminação no magistério e quiçá no mercado de trabalho como um todo. Portanto, passaremos a expor alguns dados que analisamos no nosso trabalho.

Conforme percebemos no gráfico 1, no RJ-BR 43,54\% dos inquiridos já presenciaram alguma discriminação, já em AV-PT o percentual destes é bem menor, 15,25\% (é importante referir que ninguém em AV-PT mencionou o preconceito referente à homossexualidade):

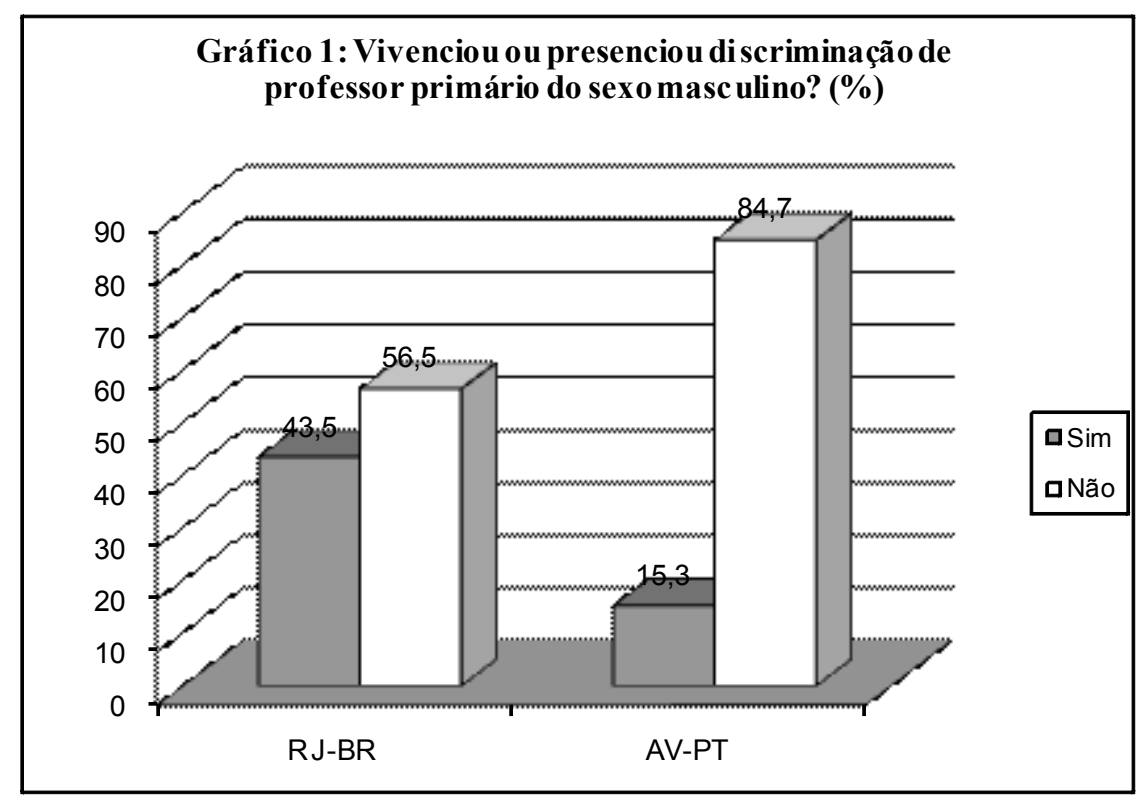

Fonte: Dados dos questionários da pesquisa.

Como este assunto contempla tabus, ele envolve muita habilidade e cautela tanto nas entrevistas quanto nos inquéritos distribuídos, por isso nos inquéritos perguntamos se havia sofrido ou presenciou alguma discriminação contra professor do sexo masculino no ensino "primário", mas não perguntamos se o professor era homossexual, por achar que não cabia no inquérito (também este não era nosso objetivo), somente nas entrevistas onde poderíamos contextualizar tal pergunta 
melhor e conduzir melhor de uma forma que levasse a uma resposta sincera, conforme descreveremos posteriormente.

No gráfico 2 categorizamos os preconceitos que foram citados nos inquéritos (uma mesma justificativa pode estar em mais de uma classificação):

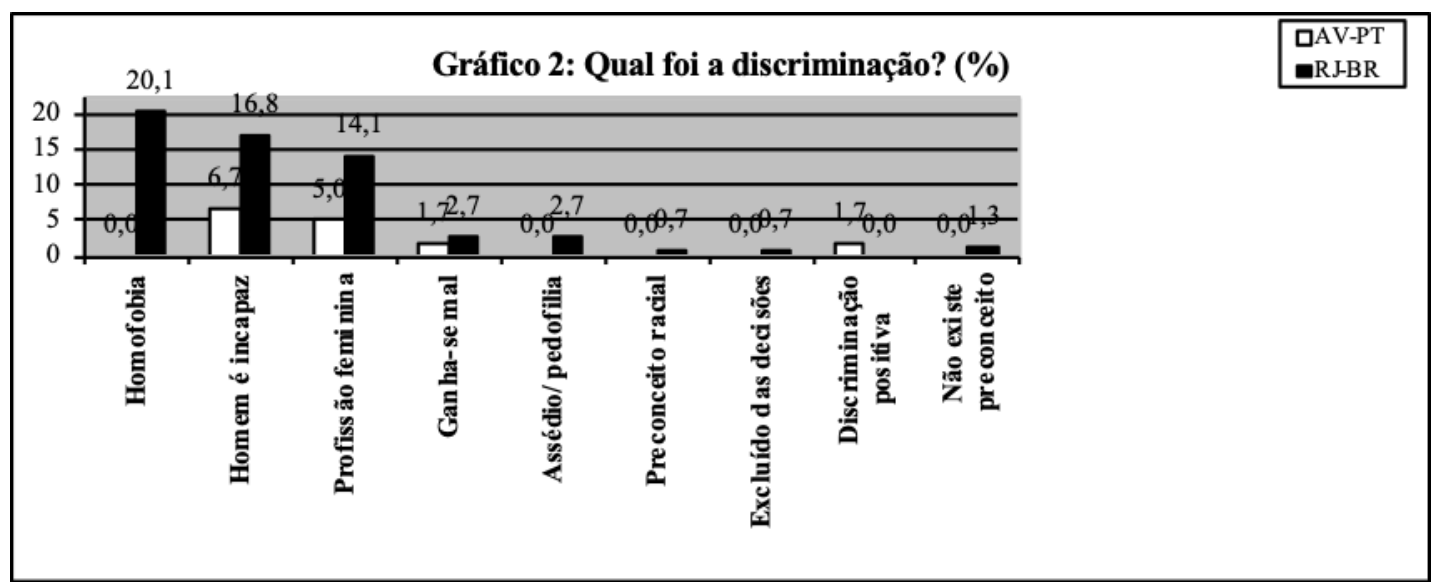

Fonte: Dados dos questionários da pesquisa.

Uma das discriminações contra o professor primário do sexo masculino é a homofobia contra o professor, que se baseia na representação preconceituosa de que todos os professores do ensino primário do sexo masculino são homossexuais.

Segundo Borrillo (2010), a homofobia (termo que surgiu nos EUA em 1971 e que aparece nos dicionários franceses na década de 1990) é um fenômeno complexo e variado que pode ser manifestado nas piadas vulgares que ridicularizam o indivíduo considerado efeminado, até formas mais brutais, chegando à violência. Assim é um fenômeno invisibilizado por ser naturalizado, incorporado ao senso comum. Por isso, para o autor a homofobia situa-se no mesmo plano excludente que o racismo, o antissemitismo ou a xenofobia.

Destaca-se que a homofobia aplica-se não só aos homossexuais, mas a toda pessoa que tem ou parece ter alguma qualidade que se atribui ao outro sexo, esta discriminação se faz nos pequenos detalhes, como no jeito corporal, na voz e nas atitudes/opções (Welzer-Lang, 2001). Analisando essa questão frente aos dados que obtivemos com a pesquisa, percebemos que o próprio fato de estar em uma profissão socialmente considerada como feminina é alvo de homofobia e, muitas vezes (como verificaremos nas entrevistas e inquéritos), pode ter repercussões na dificuldade de arrumar emprego (embora os nossos entrevistados não demonstraram tal dificuldade de conseguir emprego), na necessidade que o professor tem de reafirmar a sua masculinidade ou no pensamento em abandonar tal profissão.

Questionamos então frente às dificuldades encontradas pelos professores se seria realmente necessário afirmar-se enquanto homem na docência do ensino primário? Existiria algum impedimento para que um homossexual seja professor? 
Assim, temos como objetivo neste artigo analisar as consequências da escolha profissional destes professores que se enveredam por uma área tipicamente associada com o feminino, uma associação tão forte que estes professores parecem um "corpo estranho" no cotidiano das escolas públicas "primárias" e que podem lhe trazer preconceitos.

Já havíamos presenciado tal preconceito no RJ-BR relacionado a alguns professores das séries iniciais do sexo masculino, bem como confirmamos em pesquisas acadêmicas que esta discriminação existe em outros locais do Brasil (Abreu, 2002; Carvalho, 1998; Pincinato, 2004; Sayão, 2005), por isso considerávamos que também encontraríamos tal representação em Portugal. No entanto, para a nossa surpresa, esta não apareceu. A falta deste preconceito foi questionado nas entrevistas com professores portugueses que confirmaram a sua não-existência.

Por isso, questionamos: será que as fronteiras de gênero são menos rígidas em Portugal do que no Brasil? Pode ser que a violência homofóbica seja menor em Portugal do que no Brasil (pois o Brasil é citado no estudo de Venturi e Bokany (2011) como provável lider internacional do Brasil em crimes homofóbicos), mas isso não significa que não exista homofobia em Portugal, pois o estudo organizado por Nogueira e Oliveira (2010) mostra que Portugal é um país muito homofóbico, o que se manifesta muito em insultos, repetidas "brincadeiras", comentários nos meios midiáticos, violência doméstica, etc.

Como alguns estudos mostram (Nogueira \& Oliveira, 2010; Venturi \& Bokany, 2011) o fenômeno de atribuir os preconceitos aos outros sem reconhecer o próprio é comum, pois a atitude preconceituosa é politicamente incorreta. Assim, como não perguntamos eles tinham preconceito, mas se eles tinham conhecimento de preconceito contra professor do sexo masculino (ou se sofreram) consideramos que a resposta foi mais próxima da realidade 4 , portanto relacionamos esta falta de preconceito com a baixa associação em Portugal da necessidade de "atributos femininos" para esta profissão, o que se demonstra nos nossos dados na nãoexistência de tal preconceito e na menor quantidade de discriminações demarcadas pelos professores portugueses frente aos brasileiros.

\section{A homofobia contra o professor primário do sexo masculino}

A dominação masculina e o heterocentrismo são os paradigmas que têm condicionado nossas representações e nossas práticas (Welzer-Lang, 2001, p. 465), eles fazem com que a virilidade seja buscada pelo homem ao se afastar da feminilidade, ou seja, "Não se nasce Homem, nem se é Homem, empenhase constantemente na busca de tornar-se Homem. A virilidade representa justamente o investimento numa rede de relações com a busca do reconhecimento

4 O que confirmamos depois junto a outros professores em várias formações contínuas sobre gênero e sexualidade que oferecemos. 
da masculinidade" (Areda, 2006, p. 1). Como explica Welzer-Lang (2001, p. 465) "na socialização masculina, para ser um homem, é necessário não ser associado a uma mulher. O feminino se torna até o pólo de rejeição central".

Desta forma, as relações sociais entre homens são estruturadas na imagem hierarquizada das relações homens/mulheres e produz a homofobia para que, com ameaças, os homens se calquem sobre os esquemas ditos normais da virilidade. Também percebemos diversas questões sobre esta produção da virilidade no livro organizado por Corbin et al. (2013) sobre a história da virilidade.

Neste sentido, Welzer-Lang define a homofobia como "a discriminação contra as pessoas que mostram, ou a quem se atribui, algumas qualidades (ou "defeitos") atribuídos ao outro gênero. A homofobia engessa as fronteiras do gênero”. Por isso, "os homens que não mostram sinais redundantes de virilidade são associados às mulheres e/ou a seus equivalentes simbólicos: os homossexuais" (2001, p. 465).

Outra forma de preconceito que o autor cita é o heterossexismo que é a discriminação e a opressão baseadas em uma distinção feita a propósito da orientação sexual, ou seja, é a promoção incessante, pelas instituições e/ou indivíduos, da superioridade da heterossexualidade e da "subordinação" da homossexualidade. Ser homem corresponde ao fato de ser ativo. Este preconceito distingue os ativos, penetrantes, dominantes dos que são penetrados, dominados e ameaça estes de serem associados e tratados como mulheres. A homofobia, porém, se aplica aos homossexuais, bissexuais, transsexuais porque eles não adotam (ou suspeita-se) configurações sexuais naturais (Welzer-Lang, 2001, p. 468).

Completando, o autor cita que:

Este homem viril na apresentação pessoal e em suas práticas, logo não afeminado, ativo, dominante, pode aspirar a privilégios do gênero. Os outros, aqueles que se distinguem por uma razão ou outra, por sua aparência, ou seus gostos sexuais por homens, representam uma forma de não-submissão ao gênero, à normatividade heterossexual, à doxa de sexo e são simbolicamente excluídos do grupo dos homens, por pertencerem aos "outros", ao grupo dos dominados/as que compreende mulheres, crianças e qualquer pessoa que não seja um homem normal (Welzer-Lang, 2001, p. 468).

A homofobia aplica-se, então, não só aos homossexuais, mas a toda pessoa que tem (ou parece ter) alguma qualidade que se atribui ao outro sexo. Como Torrão Filho (2005, pp. 145-146) explica que em muitos lugares, principalmente na América Latina, a homossexualidade masculina é vista sob uma dupla moral: ativos e passivos são encarados de maneira diferente, os ativos muitas vezes não são considerados homossexuais, porque eles continuam dominando e não são penetrados. Muitas vezes, a masculinidade e a virilidade são valorizadas em detrimento dos maneirismos femininos, mesmo entre os homossexuais. 
No entanto, como explica Louro (2000), a masculinidade é mais cultivada e a não-virilidade mais vigiada (e mais visível). Porém, o estigma de que são vítimas os homossexuais, como menciona Bordieu (1998), pode ser escondido. Goffman (1963, p. 58) mostra que a questão do encobrimento levanta o problema da 'visibilidade' de um estigma particular, ou seja, até que ponto o estigma está adaptado para fornecer meios de comunicar que um indivíduo o possui.

Desta forma, talvez por causa da possibilidade dos homossexuais ocultaremse, percebemos que a homofobia sobre os homens é mais aplicada nos pequenos detalhes como jeito corporal, voz e atitudes/opções. Welzer-Lang (2001, p. 465) cita uma pesquisa feita por Piter Dutey que entrevistou pessoas sobre a forma como elas reconheciam pessoas homossexuais na rua, na sua grande maioria, elas falam de homens homossexuais (não de mulheres) e associam aos homossexuais os homens que apresentam sinais de feminilidade (voz, roupas, jeito corporal).

Dois entrevistados nos descrevem esta vigilância5 ${ }^{5}$ Destaca-se que para esta investigação não importa se os professores são ou não homossexuais, mas se estes sofrem este preconceito.

Vinícius (RJ-BR) afirma que não é homossexual, mas que, desde a infância, já sofreu várias acusações de que ele seria por causa da sua voz (ele tem a voz fina e se trata com uma fonoaudióloga, pois sabe que as pessoas confundem esse problema com a homossexualidade), conforme descreve o entrevistado:

Eu vou a uma fonoaudióloga, minha voz até melhorou, é um problema de voz que eu tenho, [...] tive que fazer uma prova de voz e fui reprovado, aí eu tive que ir pra fonoaudióloga fazer todo um tratamento [...], por isso a minha voz até engrossou, realmente a minha voz era um pouco mais fina do que essa. No telefone parece, $[. .$.$] na caixa postal do meu celular, nem eu$ falo, porque parece que é uma mulher, às vezes você me vendo falar não parece tanto, porque eu acho que você vê a pessoa, agora no telefone parece. Eu nunca gostei da minha voz [...] eu odiava a minha voz, [...] com essa questão de dar aula, a voz fica muito rouca, então a voz já vai engrossando mais. [...] Um problema com o meu pai que eu tive era com a minha voz (Vinícius, RJ-BR).

O mesmo entrevistado sente-se discriminado pelo seu jeito desengonçado de mexer muito as mãos e, também, por causa da sua sensibilidade, como ele diz "eu sou muito carinhoso, então homem não é carinhoso, homem não chora, homem não tem jeito pra cortar, pra colar, pra fazer frufru, então eles querem chamar a gente de bicha? Por mim pode me chamar, eu não tenho nada pra provar a ninguém, hoje eu já

5 Utilizaremos neste artigo nomes fictícios para os entrevistados seguido do local que eles são (RJ$\mathrm{BR})$, bem como as siglas IBR para os inqueridos por questionário no Brasil somado com a numeração do questionário, e IPT para os inqueridos por questionário em Portugal somado com a numeração do questionário. 
to nessa etapa, eu também tive muito medo disso tudo, então eu tive que me afirmar como homem".

Por causa destas acusações, Vinícius chegou a ter dúvidas da sua sexualidade de tanto ouvir as pessoas suspeitarem e teve uma experiência homossexual que fez com que ele reafirmasse sua heterossexualidade, ou seja, ele experimentou e viu que não é o que gosta:

Realmente eu experimentei e não é minha praia, mas eu sei que eu não sou um homem como padrão [...] não sou um homem 'machão', eu sou um homem sensível, eu sou carinhoso, eu sou cuidadoso, até por isso eu tive uma namorada que ela me chifrou feio, mas porque? Porque eu sou bobo, porque eu tudo olhava pra ela, na questão do vamos pensar, vamos ser sensíveis, não sei quê. Então é realmente estranho, mas eu acho que eu fiquei muito mais macho depois que eu comecei a trabalhar [...]. Filho criado por vó é um negócio sério, a minha avó sempre teve interferência na minha educação, realmente a minha avó me educou mal, então chegou uma época quando era menor que realmente eu tive problemas, as pessoas confundiam e faziam coisas que eu não gostava (Vinícius, RJ-BR).

O professor André (RJ-BR), que nos assumiu ser homossexual, disse que também teve problemas com o seu gestual e modo de andar, uma professora primária chamou a sua avó para dizer (na sua frente) que ele era diferente e tinha trejeitos femininos, que talvez isso era por não ter pai, e que tinha que mudar. Depois disso passou a tentar controlá-lo, corrigindo a todo momento o seu andar que deveria ser reto, direito, igual de homem:

A professora da $2^{\underline{a}}$ dizia que eu era diferente. Ela chamou a minha avó uma vez pra conversar e pra falar que eu tinha trejeitos femininos e que eu tinha que mudar, que isso era porque eu não tinha pai, e que a falta do pai era que estava ocasionando isso e aquilo. Na minha frente. Ela me falava "anda direito, bota corpo reto, bota o corpo não sei quê". Eu estava andando igual robô. Eu dizia "professora, eu ando assim, ué!", ela dizia “não, tem que andar reto, coluna reta, olha pro professor Edvaldo" que era um estagiário "você tem que fazer como ele". E eu dizia assim "mas, eu não quero ser igual a ele, quero ser eu”. Então tem essas coisas, hoje eu percebo algumas colegas quando a menina está brincando muito com menino, separa, não deixa, chama a mãe. [...] afirmam o que ela vai ser quando crescer, será que isso está determinado agora, só no fato dela brincar de brincadeiras masculinas? (André, $\mathrm{RJ}-\mathrm{BR})$ 
Além do gestual, do físico e dos atributos que estes professores possam ter que são comumente associados às mulheres (como sensibilidade, choro ou paciência), o próprio fato de estar em uma profissão socialmente considerada como feminina, com a consideração de que há "necessidade" de qualidades "ditas femininas" para exercer o ofício, é alvo de homofobia, pois esta, de acordo com Novena (2005, p. 10), pode se expressar através de várias violências: desprezo, afastamento, exposição ao ridículo, uma grande resistência em demonstrar simpatia para com sujeitos homossexuais (já que a aproximação pode ser interpretada como uma adesão a tal prática ou identidade). Isto se torna claro em várias entrevistas e inquéritos do RJ-BR (em AVPT este preconceito não foi mencionado ). Como veremos a seguir.

O Professor Vinícius (RJ-BR) já perdeu o emprego por causa do preconceito: "quando eu fui pra essa outra escola privada eu consegui observar de perto aquilo que o meu pai sempre quis me proteger. Uma mãe chega e fala assim ou você tira essa - desculpe o termo - ou tira essa "bicha preta" da escola, ou eu tiro meus filhos daqui, porque eu ia pegar os meninos dessa senhora, e aí foi o meu primeiro encontro com a questão do preconceito". Mas esta não foi a única vez que ele sentiu essa homofobia por ser professor, embora ele destaca que existe homossexual em todas as profissões, na escola pública também sofreu, mesmo que ele achasse que não sofreria preconceito no sistema público, mas viu que tem preconceito em qualquer lugar.

Um aluno seu fez um coração onde escreveu "professor Vinícius, eu te amo”, ele mostrou para a mãe que perguntou "esse cara está ensinando pederastia para vocês na escola?" (o menino nem sabia o que era pederastia) e falou "eu não quero mais você amando porque você não tem que amar ele, porque ele é homem e você é homem e homem não ama homem, etc etc etc". O menino passou a evitar encostar no professor com medo da reação da mãe. Vinícius chamou a mãe e disse "mesmo que eu tivesse uma posição sexual diferente da comum aquilo ali não interferiria no processo educacional do menino e que, eu fui grosso com ela, e falei que se ela quisesse provas [de masculinidade] eu daria a ela, mas que eu não precisaria fazer aquilo".

Outra demonstração desse preconceito aconteceu com os garis da sua escola que viraram um para o outro e disseram "olha só, tá nervosa”. Ele chorou, ficou muito chateado, e foi à direção reclamar: "vocês vão tomar uma postura ou a gente resolve isso agora ou eu vou levar isso à frente".

O Professor André (RJ-BR) também relata que sofreu homofobia na escola particular onde deu aula, mas por sorte foi apoiado. Em 1987 a escola recebeu uma carta onde dizia que tinha um funcionário que era pederasta, homossexual, e que isso traria grandes problemas para as crianças e que ela faria uma denúncia ao conselho federal de educação, assinado "mãe aflita". A diretora recebeu essa carta e chamou cada funcionário, leu a carta e fez uma inversão, perguntando se ao invés de homossexual, estivesse escrito negro, pobre, ou qualquer outro atributo pessoal que pudesse ser alvo de preconceito, colocando cada um no papel de André, e todos o apoiaram. Por fim, chamou André, explicou o que tinha acontecido e disse-lhe que todos o apoiaram. Convocou uma reunião com todos os pais de alunos, leu a carta, 
pediu que a mãe se apresentasse e retirasse seus filhos, porque ela não trabalharia para "fascista". Ninguém se apresentou, os pais presentes também foram contra essa pessoa. André se comoveu, mas ficou envergonhado por ter acontecido tal fato logo no início da sua carreira, ele levou mais de 10 anos para tocar nesse assunto. Ele acredita que pode haver muitos professores primários homossexuais (mas hoje em dia não tem como saber quem é ou não), mas isso não influencia em nada a educação que ele dará às crianças.

O professor Roberto (RJ-BR) nunca foi ofendido e explica que o preconceito existe "mas eu vou te ser sincero, nunca prejudicou em nada a minha vida, nunca ninguém me ofendeu a ponto de eu desistir", também afirma que "nunca dei liberdade pra isso, a gente tem que se impor". Considera que o preconceito existe, possivelmente por ser considerado uma pessoa diferente, porque carinho e afago não é considerado coisa de homem. Na sua opinião existem homossexuais em todas as profissões, mas conhece alguns professores primários "bem casados com filhos, não que isso seja limitador para ser homossexual ou não". Contudo, acredita que a homossexualidade não interfere no profissionalismo da pessoa (ele respeita os homossexuais, mas não é o que quer para ele nem para um filho), pois apesar de ser casado, e não ter tendência de ser homossexual, considera que se fosse seria o mesmo professor. É "melhor ser professor do que ser "macho" e ser bandido, por exemplo, cada um deve estar no trabalho que quer, se fosse coisa de mulher a gente era proibido de fazer o concurso público". Ele recrimina muito o preconceito: "a sociedade impinge muita coisa, até por falta de cultura [...]; eu acho que é nosso culturalmente, de uma cultura baixa”, por isso considera só uma pessoa "pobre de pensamento" pode pensar que todo professor primário é homossexual, pois para dizer isso era preciso comprovar que todo professor é homossexual.

Várias justificativas dos professores do RJ-BR nos questionários confirmam a existência desta representação preconceituosa na sociedade e das discriminações que eles sofreram por ter feito esta escolha profissional e praticar esse ofício:

A principal discriminação que acontecia na época e que me fez pensar em desistir do curso, talvez por ser relativamente jovem durante minha formação, tinha caráter sexual, pois os "amigos" afirmavam constantemente que esse curso era para homossexuais (IBR115).

Todas voltadas à opção sexual: ao chegar numa escola escutei a seguinte frase: “- É professor de Educação Física ou é bicha (homossexual) (IBR71).

Associavam a carreira à homossexualidade (no caso dos homens) (IBR8o); Muitos diziam que quem faz normal é homossexual (IBR87).

A questão da orientação sexual (IBR93).

Não pude trabalhar em uma escola particular por ser homem e as mães não iriam "entender". Na época do curso normal, achavam que eu era afeminado por causa do uniforme e da escolha. No 
próprio município do Rio, causa espanto quando me apresento (IBR95).

Relacionam escolha profissional à sexualidade do estudante (IBRio3).

Todos acham que professor do E.F. tem que, necessariamente, ser homossexual (IBR117).

Quando comecei a estudar no Curso Normal havia em minha cidade a 'propaganda' de que os homens que estudavam para ser professor eram homossexuais (IBR131).

Homem que faz magistério é bicha, veado, gay etc... e, principalmente, sem perspectivas futuras" (IBR156).

Muitas pessoas supunham que escolhi esta profissão porque era homossexual e lançavam olhares insinuantes. Alguns professores me faziam pouco caso (IBR194).

Estas justificativas mostram como esta representação preconceituosa de que o curso de formação de professores ou o próprio ofício era para homossexuais marca os professores primários, tanto que repercutem, muitas vezes, na dificuldade de arrumar emprego ou no pensamento em abandonar tal profissão (quantos não abandonaram por este motivo?). Outras justificativas mostram como este preconceito leva a um sofrimento e uma tentativa de afirmação da masculinidade:

Durante o curso, ouvi diversas vezes que homem que cursava normal só poderia ser 'boiola' (não sou), levava na esportiva e curtia o paraíso que era o curso normal com todas aquelas gatas! (IBR143).

O curso era para mulheres. Um homem no meio parecia coisa de homossexual. Porém, esta figura foi se diferenciando à medida que os relacionamentos heteros foram surgindo... na verdade este foi até um indicativo para que outros homens (de fato) procurassem o curso (IBR201).

Existia um outro aluno homossexual e isso era motivo de generalização. Então era necessário se impor para ser reconhecido como heterossexual. Ser negro, também foi pontual em minha formação (IBR122).

Muitos pensam até hoje, que todo professor de $1^{\underline{a}}$ a $4^{\underline{a}}$ série é homossexual. Apesar de respeitar o homossexual fico chateado quando fazem o seguinte comentário: "Ele pensava que você era gay”... É chato passar por isso. Homem nenhum merece. Só porque trabalho com crianças? Muitos precisam rever seus conceitos (IBR97).

Assim, como nossos entrevistados Vinícius e Roberto mostram e como foi destacado por vários autores, estas explicações indicam a necessidade de "se impor como homem", até mesmo buscando relacionamentos heterossexuais para afirmar sua masculinidade, pois como afirma Torrão Filho (2005, p. 144) "a maior ansiedade 
com relação à homossexualidade, para os homens, está nesta identificação com o feminino, com o ser dominado por outro", então o homem deseja mostrar que domina e que não é feminino.

É preciso questionar se é necessário afirmar-se enquanto homens e se há algum impedimento para que um homossexual seja professor. Como explica Sayão (2005, pp. 259-260) a heterossexualidade compulsória é algo que atormenta as mentes de profissionais e de algumas famílias, a homossexualidade ainda é concebida como um problema na cultura escolar, mas as interações que meninos e meninas vivenciam com adultos homossexuais, bissexuais, heterossexuais ou com qualquer outra orientação sexual não são determinantes de sua própria orientação, pois a atribuição de gênero é insuficiente para a identidade de gênero; a identidade de gênero é uma construção subjetiva, um sentimento de ser homem ou mulher elaborado ao longo da vida.

A consideração de que a homossexualidade é "anormal" e a própria homofobia, levam que muitos homens da nossa sociedade tenham a necessidade de afirmarse como "homem" (leia-se heterossexuais). É preciso questionar o que percebemos como normal.

Como explica Novena $(2005$, p. 7 ; 12) a repressão e a não aceitação da homossexualidade ainda são mais evidentes nas representações atuais, mas hoje o discurso da normalidade também aparece, porém esta normalidade pode representar o que Foucault nomeou de poder normativo, onde a norma não teria por função excluir e rejeitar, mas ela representaria um poder que é inventivo, que controla a intervenção, a transformação e a inovação, um poder que incorpora este outro diferente/desviante com a intenção de transformá-lo num outro igual/normatizado. Mesmo assim, o discurso da normalidade pode permitir a intensificação e aprofundamento das discussões a respeito das sexualidades alternativas, propiciando a possibilidade de mudança quanto à assimilação e aceitação do outro diferente, repercutindo com isso na produção das subjetividades.

Bordieu (1998, pp. 101-105) destaca que para transformar duradouramente as representações deve-se operar e impor uma transformação duradoura das categorias incorporadas, para isso é preciso obter o direito "à visibilidade invisível do bom soldado, do bom cidadão, do bom cônjuge", reivindicar estes direitos, paradoxalmente, pode levar a uma condenação ainda maior, pois os estigmatizados tornar-se-ão visíveis (antes estes eram oprimidos pela "invisibilização" que traduz-se por uma recusa da existência legítima, pública), ou seja, a estigmatização nunca se mostra tão claramente como quando o movimento reivindica a visibilidade. Enfim, o objetivo do movimento de subversão simbólica é fazer uma destruição e construção simbólica "visando impor novas categorias de percepção e de apreciação, de maneira a construir um grupo ou, mais radicalmente, a destruir o próprio princípio de divisão segundo o qual são produzidos tanto o grupo estigmatizante como o grupo estigmatizado. Trata-se de um trabalho para cuja realização os homossexuais se encontram particularmente bem armados, podendo pôr ao serviço do universalismo, nomeadamente nas lutas subversivas, as vantagens ligadas ao particularismo". 
Destacamos, então, como afirma Torrão Filho (2005, p. 148), que a homossexualidade não é um problema em si para a história nem para a sociedade, mas sim a sua repressão: a homofobia.

\section{Conclusão}

Ao questionar sobre "Quem tem mais aptidão para o magistério primário?" surpreendemos-nos com as respostas dos inquiridos e entrevistados. Houve uma quantidade grande de professores (principalmente no RJ-BR) que considerou que a mulher tinha maior aptidão para o magistério primário, alguns que diziam ser o homem e uma maioria que se dizia indiferente. Contudo, muitos dos que demarcaram que a aptidão era indiferente ao sexo continuavam a delimitar divisões dos papéis sexuais nas suas respostas (por exemplo a mulher seria maternal, carinhosa e paciente e o homem seria paterno, controlador e profissional), o que confirma que os homens em ocupações tradicionalmente femininas nem sempre são desprovidos de preconceitos (mesmo os que ultrapassam dificuldades e discriminações) e por vezes apóiam a masculinidade hegemônica para afirmar a sua masculinidade e competência, como na utilização de algumas afirmativas nos questionários como: "Homem é mais profissional", "Homem tem mais controle", "Homem relaciona-se à figura paterna", "Cada sexo tem seu papel”, "Homem tem vocação", "Homem tem mais perfil/aptidão", "Mulher é mais sensível/paciente/carinhosa”, "Mulher é maternal”, "Mulher é melhor na pré-escola”.

Apesar de encontramos muitas representações de gênero preconceituosas entre as respostas dos professores a esta pergunta, a maioria dos professores do sexo masculino no ensino primário não apontaram preconceitos e mostraram que estão introduzindo contradições e ressignificando relações de gênero. Algumas das frases ditas foram:

Homens e mulheres têm as mesmas aptidões, o que difere são as expectativas sociais sobre o sujeito (IBR103).

Aptidão não tem nada a ver com sexo, é amor e formação adequada (IBR107).

Na minha opinião somos todos iguais; hoje em dia não existem diferenças; mas infelizmentevivemos num país preconceituoso, onde alguns se dizem melhores que os outros (IBR125).

Ambos têm a mesma aptidão, embora a sociedade tenha estigmatizado que esta profissão é mais adequada para as mulheres (IBR8o).

Tanto homens ou mulheres têm condições de serem professores, indiferente de sexo ou raça (IBR178).

Se sabemos e gostamos do que fazemos, certamente realizamos o melhor. O profissional deve estar capacitado, não importando o sexo (IBR120). 
Acredito que o indivíduo bem preparado e consciente de suas responsabilidades é capaz de desempenhar suas atividades de forma satisfatória (IBR203).

Nunca me apercebi de aptidões específicas deste ou daquele sexo para o exercício da profissão (IPT4).

Não tem qualquer relevância o sexo do professor, a relação professor-aluno poderá ser exactamente igual qualquer que seja o sexo do professor e aluno (IPT10).

Isso depende da pessoa não do sexo (IPT25).

Penso que é indiferente desde que cada um tenha a consciência de desenvolver a melhor forma de ensinar e ir modelando a sua forma de estar na docência (IPT33).

O saber lidar com crianças ou ser bem aceite por ela não é exclusivo de nenhum dos sexos (IPT36).

Não me parece que o magistério do 1. ciclo exija algo que só homens ou só mulheres possam fazer. Aliás, penso que a totalidade das actividades profissionais tanto podem ser desempenhadas por homens como por mulheres (IPT6o).

Eles são homens que estão na escola repensando os papéis masculinos e femininos nas profissões, por estar introduzindo mudanças nos papéis de gênero acabam por sofrer muitas discriminações que foram relatadas e descritas por nossos entrevistados e inquiridos (mais no RJ-BR, onde quase metade dos professores já presenciaram ou sofreram alguma discriminação, do que em AV-PT).

Uma das discriminações que se destacaram foi a homofobia contra o professor, que faz com que homens não escolham esta profissão ou que tenham que reafirmar a sua masculinidade e competência no exercício do seu trabalho. Será que é mesmo necessário afirmar-se enquanto homem na docência do ensino primário? Há algum impedimento para que um homossexual seja professor?

Nas entrevistas os relatos foram recheados de emoções que envolveram a não aceitação familiar da escolha profissional, a implicância de colegas associada ao baixo rendimento e homossexualidade (no caso de dois professores brasileiros, que sofreram homofobia, um que assumiu a sua homossexualidade e o outro que afirmou não ser homossexual), os olhares "estranhadores”, a discriminação declarada e anônima (até mesmo uma carta anônima foi enviada para uma escola no RJ-BR pedindo a saída do professor), entre outras.

Como dissemos anteriormente a homossexualidade não é um problema, mas sim a homofobia, que acaba por gerar também a necessidade de afirmar-se como "homem". É preciso intensificar e aprofundar as discussões a respeito de todas as formas de sexualidades, propiciando a possibilidade de mudança quanto à assimilação e aceitação do outro, repercutindo com isso na produção das subjetividades. Como demarca Seffner (2011, p. 571): "Existe uma vinculação clara entre o respeito à diferença sexual e de gênero e a qualidade das aprendizagens 
escolares. Políticas de equidade promovem um ambiente escolar mais sadio para todos e todas, diminuindo preconceitos e situações de baixa autoestima”.

Enfim, a escola precisa ser um espaço de respeito e não de divulgação de preconceitos. Como destaca Borrillo (2010) a escola tem um papel importante na prevenção da homofobia mostrando o direito e o respeito a outras formas de sexualidade. Entretanto, ao contrário disso, como a pesquisa do INEP demonstrou (Mazzon, 2009):

os diversos públicos-alvo (diretores, professores, funcionários, alunos e pais / mães) apresentam atitudes, crenças e valores percebidos que indicam que o preconceito é uma realidade nas escolas públicas brasileiras nas sete áreas temáticas de discriminação pesquisadas (étnico-racial, de deficiência, de gênero e orientação sexual, geracional, socioeconômica e territorial).

A pesquisa confirmou que a maioria das vítimas encontram-se no corpo discente, mas funcionários/as e docentes também tem sido alvo desta discriminação que resultam em situações em que pessoas são humilhadas, agredidas ou acusadas injustamente simplesmente pelo fato de fazerem parte de algum grupo social específico (no caso dos/as professores/as mais por ser idoso, homossexual ou mulher). Por fim, a pesquisa demarca que a mudança desse ambiente discriminatório leva muitos anos, mas é preciso iniciar já ações que disseminem de informações e implementações que promovam a mudança de valores dos agentes escolares em relação à questão discriminatória.

Uma destas ações estaria na formação de professores/as para lidar com questões de gênero e sexualidade, mas estas tem sido escassas, pois vários autores (Altmann, 2003; Azevedo, 2005; Cafardo, 2006; Marques \& Knijnik, 2006) referem que a formação inicial e contínua dos/as professores/as não tem dado conta das questões de gênero e sexualidade (o que é confirmado pelo censo do magistério brasileiro, onde só $0,25 \%$ de todas as formações contínuas foram específicas de sexualidade e gênero, ver Brasil, 2006, p. 292). Por isso os/as docentes quando indagados a respeito do gênero e da sexualidade expõem desinformação e falta de preparo (ver Reis, 2002; Schindhelm, 2008). Tal desinformação dos/as professores/as gera preconceitos sexuais e generificados sobre a profissão docente, conforme verificado em outras investigações (Araújo, 2000; Sarmento, 2002; Williams, 1995; Yannoulas, 2001). Por tudo isso é preciso formar os/as professores/as para que entendam melhor as questões de gênero e sexualidade na sua vida e prática pedagógica, pois estas estão sempre presentes nos contextos escolares e afloram nos mínimos detalhes da função docente.

É preciso que não exista discriminação com base em gênero nem orientação sexual, tanto na escolha profissional, na empregabilidade nem na atuação profissional (o que acontece muito na nossa sociedade, ver por exemplo Rodrigues \& Nardi, 2009), 
pois ambos os gêneros podem escolher e ser capazes de exercer qualquer profissão, independente da sua orientação sexual, por isso nem o fato de ser homem deveria levar a estranhamentos com relação a sua capacidade de trabalho nem mesmo o fato dele escolher esta profissão levar a um questionamento da sua orientação sexual, seja ele homossexual ou heterossexual, pois isso não afetará o seu trabalho, ao contrário da discriminação que afeta muito no trabalho e na vida dos indivíduos.

Apesar da quantidade das discriminações sobre o professor do sexo masculino ser menor em AV-PT, ainda encontramos algumas. A discriminação que mais encontramos em AV-PT foi a de que o "homem não tem dom para lidar com crianças", esta foi a segunda maior no RJ-BR. Esta discriminação pode não ser tão "forte" como a consideração de que todos os professores do sexo masculino seriam homossexuais, mas tem suas bases nos mesmos critérios de gênero que levam alguém a julgar que um homem é homossexual, ou seja, as qualidades e papéis de cada gênero. Mas o olhar se inverte: ele é homem, por isso não tem as características femininas que são essenciais para ser um bom professor primário.

Discrimina-se o professor do sexo masculino por ser "diferente" da maioria, considerando que por este fato não têm qualidades para ser professor primário. Algumas vezes esta discriminação foi associada à homofobia, pois ou ele tem as características femininas e é considerado homossexual ou ele tem características masculinas e não tem estas características femininas e, por isso, não tem aptidão para o magistério.

Os professores entrevistados de Portugal e a autora Teresa Samento (2002) nos permitem inferir que a discriminação homofóbica contra os professores se desloca mais para um nível escolar anterior, a educação de infância, como descrevem nossos entrevistados (embora não investigamos junto aos educadores de infância). Joaquim (AV-PT) diz que não há preconceito contra o professor primário do sexo masculino, principalmente a suspeita de que seriam homossexuais, mas "isso pode acontecer, e aconteceu, muito com os educadores de infância, com os educadores culturais e com os enfermeiros. Eu não estou dizendo que não aconteça, comigo nunca aconteceu". José (AV-PT) também explica que nunca viu discriminação com relação a ser professor do sexo masculino. Mas sente mais essa discriminação, por exemplo, a nível de educadores de infância.

Assim, a ausência da homofobia pode ser explicada porque em Portugal este nível de ensino não é associado tanto à necessidade de dom maternal e que, nesse sentido, o homem pode ser professor sem tantos problemas e até com alguma vantagem (conforme referido em RABELO, 2010;2013).

Enfim, a escola tem sido lugar de preconceitos e discriminações (sobre este assunto ver também Abramovay, Castro, \& Silva, 2004; Abramovay, Cunha, \& Calaf, 2009), especialmente contra discentes e docentes, em nosso cotidiano também já havíamos presenciado a homofobia na escola, que se aplica a todos que apresentam algo diferente, aparentando-se com homossexuais ou mulheres, no caso do professor primário do sexo masculino esta proximidade dar-se-ia pelo simples fato dele escolher e trabalhar em uma profissão feminina e lidar com crianças. $\mathrm{O}$ fato de não termos 
encontrado esta discriminação em Portugal nos mostrou como estas fronteiras de gênero são construídas com base em alicerces frágeis (pequenos detalhes), mas que fazem crescer grandes edifícios que são os preconceitos.

Neste sentido, defendemos que a entrada dos homens no magistério primário pode mostrar a todos (tanto para as crianças, assim como para os seus pais, mães e para os outros profissionais e pessoas que o vêm nesta profissão) que o homem pode ter sucesso exercendo esta profissão, por isso esta profissão não é somente feminina. Isto porque, apesar das discriminações, notamos que estes professores são, na maioria das vezes, bem recebidos e considerados habilidosos no seu exercício profissional, o que contraria os estereótipos e acaba por divulgar socialmente que nem a docência nem as qualidades "tradicionalmente femininas" são específicas das mulheres.

Salientamos que a simples entrada de homens no magistério pode ajudar a mudar a definição da masculinidade e incluir as qualidades ditas "femininas" nesta, pois as crianças com que estes professores primários lidam poderiam se identificar com novos modelos masculinos exercendo estas atividades. Elas teriam outros modelos de homens que não percebem o trato com crianças como uma tarefa somente feminina e que podem incluir aspectos considerados "femininos" na sua masculinidade, dessa forma, sua presença nestas ocupações pode mudar as distinções entre homem e mulher, mesmo que de forma sutil, que é uma etapa importante para a realização da igualdade de gênero.

Apontamos, portanto, que a presença de professores do sexo masculino na docência do "ensino primário" é uma forma de inserir as questões de gênero na educação, mostrando que existem outros temas e outras vozes que ecoam nas escolas, ou seja, indivíduos capazes de exercer esta profissão independente do seu sexo.

\section{Referências bibliográficas}

ABRAMOVAY, Miriam; CASTRO, Mary Garcia; SILVA, Lorena Bernadete da. Juventude e sexualidade. Brasília: UNESCO Brasil, 2004.

ABRAMOVAY, Miriam; CUNHA, Anna Lúcia; CALAF, Priscila Pinto. Revelando tramas, descobrindo segredos: violência e convivência nas escolas. Brasília: RITLA, SEEDF, 2009.

ABREU, Jânio Jorge Vieira de. A inserção do professor do sexo masculino no magistério primário de Teresina (PI). Artigo apresentado em II Congresso Brasileiro de História da Educação: História e Memória da Educação Brasileira, Natal, Brasil, 2002.

ALTMANN, Helena. A construção social da orientação sexual na escola. Artigo apresentado em 26. a Reunião Anual da ANPEd, Poços de Caldas, MG, Brasil, 2003. 
ARAÚJO, Helena Costa. Pioneiras na educação: as professoras primárias na viragem do século: contextos, percursos e experiências, 1870-1933. Lisboa: Instituto de Inovação Educacional, 2000.

AREDA, Felipe. Ser gay e a possibilidade de não ser homem. Artigo apresentado em Seminário Internacional Fazendo Gênero 7, Florianópolis, 2006.

AZEVEDO, Heloísa Helena Oliveira de. Formação inicial de profissionais de educação infantil: desmistificando a separação cuidar-educar. Tese de Doutorado em Educação, Universidade Metodista de Piracicaba, Piracicaba, 2005.

BORDIEU, Pierre. Algumas questões sobre o movimento gay e lésbico. In BORDIEU (Ed.), A dominação masculina. Oeiras: Celta Editora, 1998, p. 101-105.

BORRILLO, Daniel. Homofobia: história e crítica de um preconceito. Belo Horizonte: Autêntica editora, 2010.

BRASIL. Sinopse do Censo dos Profissionais do Magistério da Educação Básica 2003. Brasília: INEP - Instituto Nacional de Estudos e Pesquisas Educacionais Anísio Teixeira, 2006.

CAFARDO, Renata. Educação sexual ainda está longe da realidade das escolas. $\mathbf{O}$ Estado de São Paulo, 2006.

CARVALHO, Marília Pinto de. Vozes masculinas numa profissão feminina. Revista Estudos Feministas, v. 6, n. 2, 406-422, 1998.

CORBIN, Alain; COURTINE, Jean-Jacques; VIGARELLO. Georges. História da virilidade. Rio de Janeiro: Vozes, 2013.

EURYDICE. Glossário europeu da educação (Vol. 3). Brussels: Eurydice, 2001.

GOFFMAN, Erving. Estigma. Rio de Janeiro: Guanabara, 1963.

LOURO, Guacira Lopes. Currículo, género e sexualidade. Porto: Porto Editora, 2000.

MADEIRA, Ana Isabel. Estudos comparados em história da educação e educação colonial: algumas considerações sobre a comparação no espaço da língua portuguesa. Sísifo. Revista de Ciências da Educação, 1, 37-56, 2006.

MARQUES, Lílian Danyi; KNIJNIK, Jorge Dorfman. Interfaces entre orientação sexual e Educação Física: reflexões a partir de uma proposta de intervenção na escola pública de ensino fundamental ciclo II efdesportes.com - Revista Digital, ano 11, n. 103, 
2006. Acessado em 11/o8/2020 de http://efdeportes.com/efd103/orientacion-sexual. htm.

MAZZON, José Afonso (Ed.). Projeto de estudo sobre ações discriminatórias no âmbito escolar, organizadas de acordo com áreas temáticas, a saber, étnico-racial, gênero, geracional, territorial, necessidades especiais, socioeconômica e orientação sexual. São Paulo: FIPE/MEC/INEP, 2009.

MOSCOVICI, Serge. Notes toward a description of social representation. European Journal of Social Psychology, v. 18, p. 211-250, 1988.

NOGUEIRA, Conceição; OLIVEIRA, João Manuel de (Eds.). Estudo sobre a discriminação em função da orientação sexual e da identidade de género. Lisboa: Comissão para a Cidadania e a Igualdade de Género, 2010.

NOVENA, Nadia Patrizia. Representações sociais da homossexualidade e produção de subjetividades na organização escolar. Revista Ártemis, n. 3, 2005.

PINCINATO, Daiane Antunes Vieira. História do magistério: experiências masculinas na carreira administrativa no estado de São Paulo (1950-1980). Artigo apresentado em 27 $7^{\underline{a}}$ Reunião da Anped, Caxambu, MG, 2004.

RABELO, Amanda Oliveira. 'Eu gosto de ser professor e gosto de crianças? ? A escolha profissional dos homens pela docência na escola primária. Revista lusófona de educação, v. 15, p. 163-173, 2010.

RABELO, Amanda Oliveira. Professores discriminados: um estudo sobre os docentes do sexo masculino nas séries do ensino fundamental. Educação e Pesquisa (USP. Impresso), v. 39, p. 907-925, 2013.

REIS, Maria Amélia (2002). (Re)Invenção da escola pública: sexualidade e formação da jovem professora. Tese de Doutorado em Educação, UFF, Rio de Janeiro.

RODRIGUES, Manoela Carpenedo; NARDI, Henrique Caetano. Diversidade sexual e trabalho: reinvenções do dispositivo. Bagoas, n. 3, p. 127-143, 2009.

SAMPIERI, Roberto Hernández; COLLADO, Carlos Hernández; LUCIO, Pilar Baptista (2006). Metodologia de pesquisa （ $3^{\mathrm{a}}$ ed.). São Paulo: Mc Graw Hill, 2009.

SARMENTO, Teresa. Correr o risco: ser homem numa profissão 'naturalmente' feminina. Artigo apresentado em Congresso Português de Sociologia: Sociedades Contemporâneas: Reflexividade e Ação, Braga, Portugal, 2002. 
SAYÃO, Deborah Thomé. Relações de gênero e trabalho docente na educação infantil: um estudo de professores em creche. Tese de doutorado em educação, Universidade Federal De Santa Catarina, Florianópolis, 2005.

SCHINDHELM, Virgínia Georg. Educar para a sexualidade é educar para a vida? Um estudo sobre a sexualidade infantil numa creche comunitária. Dissertação Mestrado em Educação, Universidade Federal do Estado do Rio de Janeiro, Rio de Janeiro, 2008.

SEFFNER, Fernando. Um bocado de sexo, pouco giz, quase nada de apagador e muitas provas: cenas escolares envolvendo questões de gênero e sexualidade. Estudos Feministas, v. 19, n. 2, p. 561-588, 2011.

TORRÃO FILHO, Amílcar. Uma questão de gênero: onde o masculino e o feminino se cruzam. Cadernos pagu, v. 24, p. 127-152, 2005.

VENTURI, Gustavo; BOKANY, Vilma (Eds.). Diversidade Sexual e Homofobia no Brasil. São Paulo: Editora Fundação Perseu Abramo, 2011.

WELZER-LANG, Daniel. A construção do masculino: dominação das mulheres e homofobia. Estudos Feministas, n. 2, p. 460-482, 2001.

WILLIAMS, Christine. Still a man's world: Mens do women's work. Berkeley, CA: University of California Press, 1995.

YANNOULAS, Silvia. Notas para a integração do enfoque de gênero na educação profissional. In VOGEL (Ed.), Trabalhando com a diversidade do PLANFOR: raça/ cor, gênero e pessoas portadoras de necessidades especiais. São Paulo: Unesp, 2001.

Recebido em 12/08/2020.

Aceito em 02/05/2021. 